\title{
Healthcare Spending: The Role of Healthcare Institutions from an International Perspective
}

\author{
Hannes Titeca ${ }^{1}$
}

\begin{abstract}
Healthcare systems differ greatly across the world, however, it appears that the extent of public insurance (publicly/government funded healthcare) is the only institutional characteristic that plays a significant role in accounting for the large disparities in total healthcare spending. Other factors, such as whether healthcare services are provided by the private or public sector, play much less of a role, highlighting the important distinction between how services are provided and how those services are funded. A regression analysis is conducted utilising an existing categorisation of the predominately high-income countries of the OECD in 2009. It is found that more public insurance and less private insurance is associated with significantly lower spending after controlling for differences in income through GDP and healthcare quality/outcomes through life expectancy. This result is robust to the inclusion of additional controls for lifestyle factors and the proportion of the population aged 65 and over, as well as the inclusion or exclusion of the US that could otherwise be seen as some kind of outlier. A typical country relying largely on private provision and insurance, such as the Netherlands, Germany or the US, could reduce total healthcare spending by around a third by moving to a system with extensive public insurance whilst retaining extensive private provision of services, a situation typical of some countries such as Austria, Greece and Japan.
\end{abstract}

\section{Introduction}

Many people today have the opportunity to see first-hand how healthcare systems across the globe differ greatly, even between developed economies. On one extreme, there are countries such as the UK that offer universal, publically provided healthcare that is generally free at the point of delivery.

Figure 1. Total healthcare spending across OECD countries in 2012.

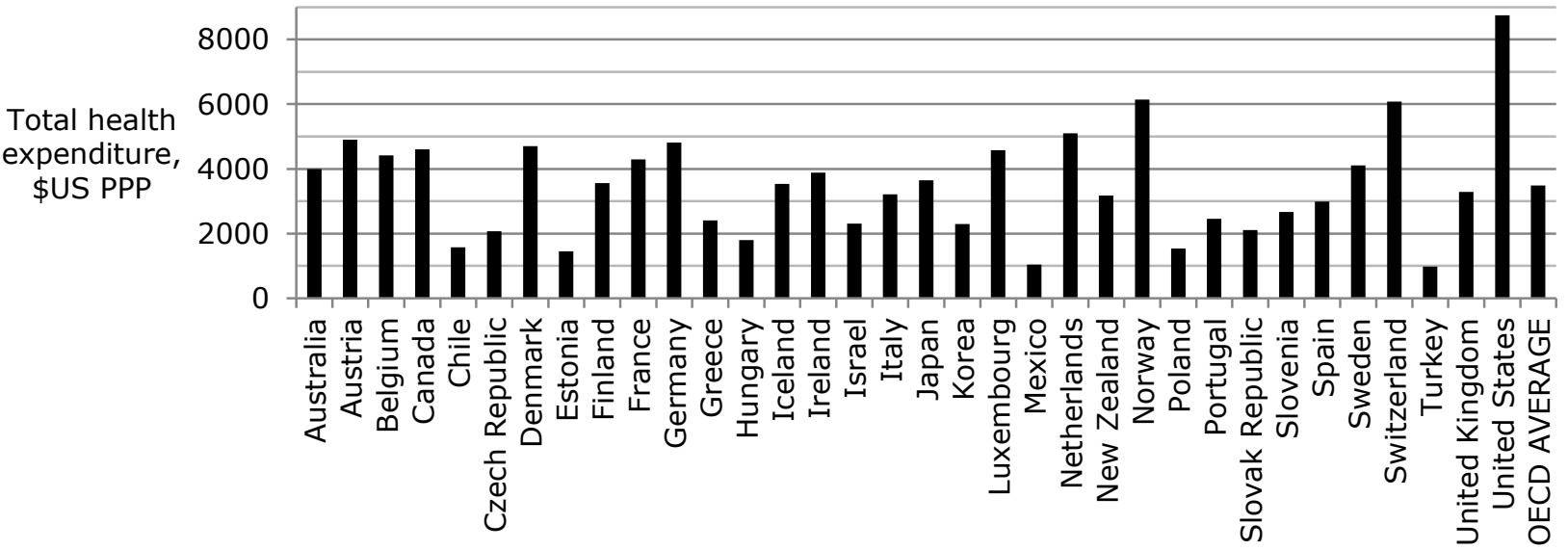

On the other extreme are systems, such as that in the US, that are based mainly on private sector healthcare provision and funding.

\footnotetext{
1 Hannes Titeca received a BSc in Economics and Business Economics (specialisation International Economic Studies) at Maastricht University in 2015 and is currently persuing an MSc and subsequent PhD in Economics at the University of Exeter as part of an ESRC " $1+3$ " studentship award. Contact: hannest@hotmail.co.uk
} 
Figure 1 uses the latest available OECD data (OECD, 2014) to show the differences in total (private and public) health expenditure per capita of the OECD countries in \$US PPP, purchasing power parity, terms for 2012. It shows how there exist large disparities among developed countries in terms of total spending on healthcare despite similar effectiveness levels in terms of metrics such as cancer survival rates (Squires, 2012). These large spending differences suggest that there is considerable room for improving healthcare systems by looking at what characterises different systems and the reasons behind any disparities.

Total healthcare spending is often looked at in terms of it as a percentage of a country's gross domestic product (GDP) to take into account the fact that richer countries with a higher GDP have a greater capacity to spend more on healthcare. This relation is disused in more detail later in this paper but it can be seen from Figure 2, which uses 2012 OECD data (OECD, 2014), that there are still considerable differences in healthcare spending when it is measured as a percentage of GDP, suggesting that there are other factors that play a significant role.

Figure 2. Total healthcare spending as a percentage of GDP across OECD countries in 2012.

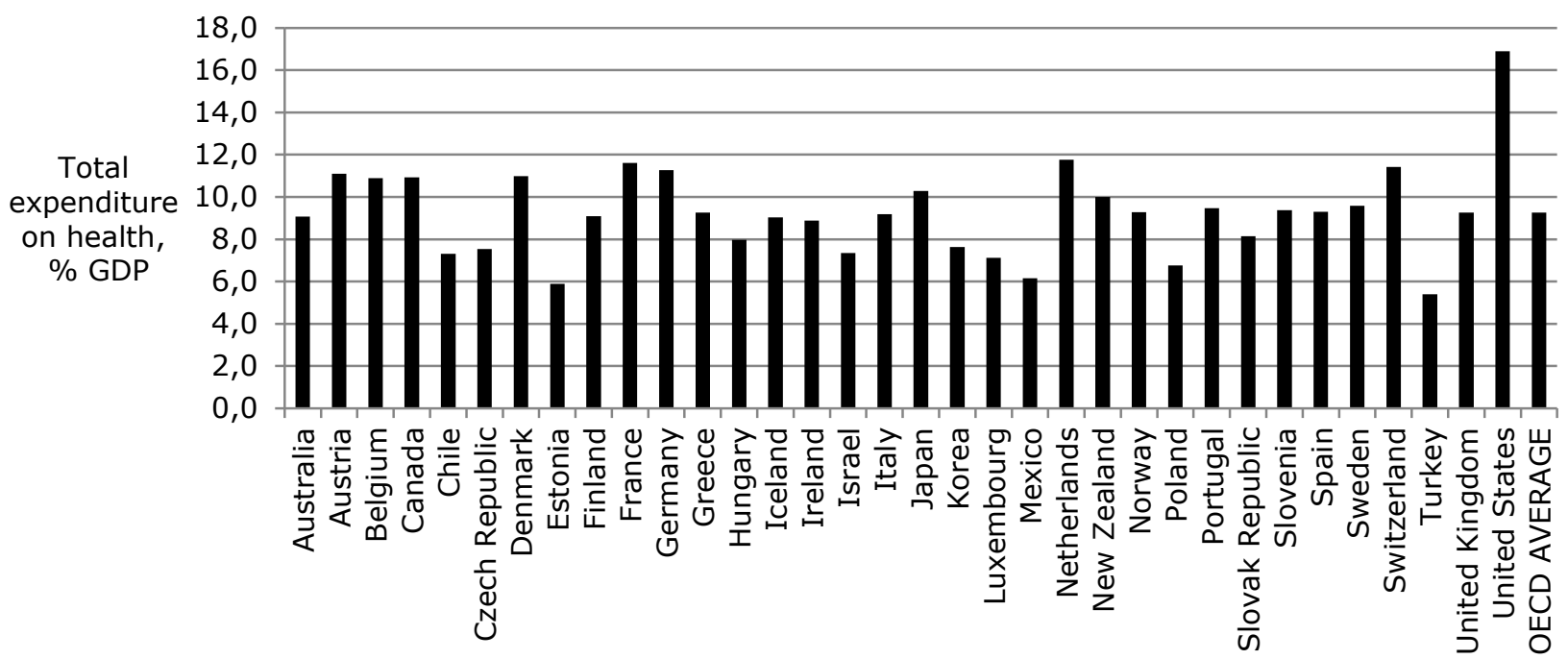

The issue of healthcare spending is one that will only increase in relevance as healthcare spending as a percentage of GDP continues to increase in many countries (OECD, n.d.). This suggests that the sustainability of healthcare system spending needs to be looked at, especially in the current economic context of high public sector debt in many countries. Healthcare provision is something that inevitably affects us all so it is an area that is worthy of detailed economic investigation in an attempt to optimise policy choices.

Different healthcare systems across the world vary widely in the level of government involvement in the free market and there exist many regulatory differences, aspects such as these can be seen as institutional differences. This role of healthcare institutions (which this paper defines as the formal policies and regulations as well as the more informal norms and arrangements that characterise healthcare systems) has been subject to relatively little research. Therefore, looking at the effect of these differences from an economic perspective allows the examination of whether different healthcare

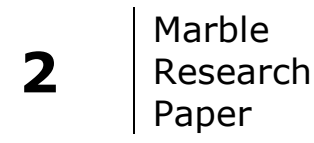


nstitutions affect healthcare spending and if so, build a theory as to how this relationship works, giving an insight into what the optimal policy choices are.

Healthcare has several characteristics that can be seen to separate it from most other goods and services such as intrinsic externalities, asymmetric information, uncertainty and the presence of a third party agent (Phelps, 2012), i.e. a healthcare professional who makes purchasing decisions on behalf of a patient whilst not bearing the costs themselves. It is intuitive that different institutions will have an effect on how these characteristics play a role in determining healthcare spending. For example, a doctor who is personally compensated for each appointment they have with a patient may have an incentive to prescribe follow-up appointments even when they are not strictly necessary. Thereby increasing healthcare spending whilst having a limited impact on healthcare quality and outcomes.

The research question that this paper will answer is therefore: How can institutional differences in healthcare systems help to account for spending differences around the world? In order to examine this question, this paper will first provide a detailed look at the relevant academic literature, followed by a description of the methodology that will be used to add to the current literature before then presenting the findings. A discussion on the results and possible policy implications concludes the paper.

\section{Literature review}

There is an abundance of existing literature that looks at specific reforms and policy changes on healthcare spending as well as on outcomes from the perspective of a single country; however, meaningful cross-country comparisons of different systems have only been possible relatively recently. Data on total healthcare spending in different developed countries has been available for several decades with the finding that "more affluent countries spend proportionally more on health care" (Anderson, Hurst, Hussey, \& Jee-Hughes, 2000) (i.e. GDP per capita is positively correlated with healthcare spending per capita) being made as early as the mid-1980s. Data on healthcare outcomes and quality that are comparable across countries have however only become available more recently with a paper published in 2000 noting the "scantiness and frailty of the data" (Anderson, Hurst, Hussey, $\&$ Jee-Hughes, 2000) that they had available.

Reinhardt, Hussey, \& Anderson (2004) confirmed the finding of previous studies that GDP per capita appears to be one of the most important factors in explaining variation in healthcare spending with a regression analysis indicating that it can account for about $90 \%$ of the variation in spending across the OECD countries in 2001. Their explanation for this being that a higher GDP per capita represents a higher ability to pay and therefore increased demand for healthcare.

Squires (2012) made the same observations in relation to spending in \$US PPP terms when using OECD data from 2009. He looked at the case of the US in relation to other developed countries and found that the US does not have a significantly higher supply or use of doctors or hospitals. In most measures the US is in fact below the OECD average, therefore suggesting that differences in utilisation cannot account for the large total spending differences between the US and other developed countries. Otherwise, it could be the case that the US has higher total costs simply because it has higher levels of use. 
Anderson, Reinhardt, Hussey, \& Petrosyan (2003) came to the same conclusion using earlier OECD data from 2000 and concluded that "the difference in spending is caused mostly by higher prices for health care goods and services in the United States".

Squires (2012) used more recent data and found there are significant price differences between countries for identical or very similar goods and services such as specific pharmaceuticals, doctor/hospital visits and specific procedures. Squires (2012), as well as other literature, also found that developed countries have similar healthcare quality levels in terms of metrics such as cancer survival rates and the US is "not notably superior to the far less expensive systems".

There is, however, little research looking at the reasons behind these apparent price differences in healthcare so it would be valuable to try to look in more detail at this from an economic perspective. Economic theory tells us that institutional factors such as different market structures, levels of competition, and government intervention are factors that can have a great impact not only on prices but also on innovation over time by affecting the extent to which companies can profit from investment into research and development (Motta, 2004).

Some research such as that by Reinhardt, Hussey, \& Anderson (2004) indicates that administrative complexity and related costs make up a significant proportion of spending in some countries. The same authors also note that buyer power differs greatly between countries with some having what is effectively a single buyer in the form of the government that holds a great deal of buyer power and hence should theoretically be in a stronger position to negotiate lower prices with suppliers. On the other hand, there are countries with many fragmented buyers that hold little buyer power.

Frank (2001) looked at this from a quantitative perspective and found that in the US, uninsured cash payers of prescription medication pay significantly more than the prices paid by the insurance providers or buyers at the hospital or federal level. This being due to differences in buyer power and the ability for sellers to successfully use differential pricing strategies. Therefore, more up to date research into whether differences between countries in the levels of buyer power exhibited by different healthcare market structures would be beneficial as this could possibly help to explain spending differences.

Much of the existing literature is quite US-centric, however, it is also useful to look at other countries such as Japan, which has a private sector dominated delivery system and has health status statistics that are among the best in the world despite spending relatively little on healthcare compared to other OECD countries (Hashimoto, et al., 2011). It has been able to accomplish cost containment mainly through a tightly controlled nationally uniform schedule set by the government (Hashimoto, et al., 2011). Other countries such as Canada, the UK, France, and Germany have also used budget and price controls as a method of healthcare cost containment with differing degrees of effectiveness (Stabile, et al., 2013).

Despite most literature looking at healthcare systems in high-income countries, there is evidence that the healthcare systems of low and middle-income countries are characterised by the same issues as

\footnotetext{
$4 \quad$\begin{tabular}{l|l} 
Marble \\
Research \\
Paper
\end{tabular}
} 
those in higher income countries. A recent systematic review of healthcare system performance in middle and low-income countries found that "the private sector appeared to have lower efficiency than the public sector, resulting from higher drug costs, perverse incentives for unnecessary testing and treatment, greater risks of complications, and weak regulation" (Basu, Andrews, Kishore, Panjabi, \& Stuckler, 2012), issues similar to those highlighted in the literature looking at high-income countries.

There is a lack of existing literature that looks to identify institutional differences across different countries in a reliable and consistent way; however, a recent OECD working paper (Joumard, André, \& Nicq, 2010) offers some insights into this area of research. It has developed a comprehensive set of 20 indicators on health policies and institutions that "allows the empirical characterisation of health care systems and the identification of groups of countries sharing similar health institutions". They identified six groups of countries sharing similar healthcare institutions with one extreme, group 1, consisting of countries such as Germany and the Netherlands that have extensive private market sector healthcare provision, i.e. things such as doctors and hospitals being supplied by the private sector, whilst also relying on basic healthcare insurance coverage from the private sector. On the other extreme, group 6 includes countries such as the UK and Italy that have mostly public provision and public insurance/funding, have strong gatekeeping systems such as enforcing patients to first contact a primary care provider before being referred for further care and have strong budget controls. The precise groupings are shown in Figure 3 and "sensitivity analysis shows that the clusters identified are fairly robust." (Joumard, André, \& Nicq, 2010).

Figure 3. Groups of countries sharing broadly similar institutions. (Joumard, André, \& Nicq, 2010)
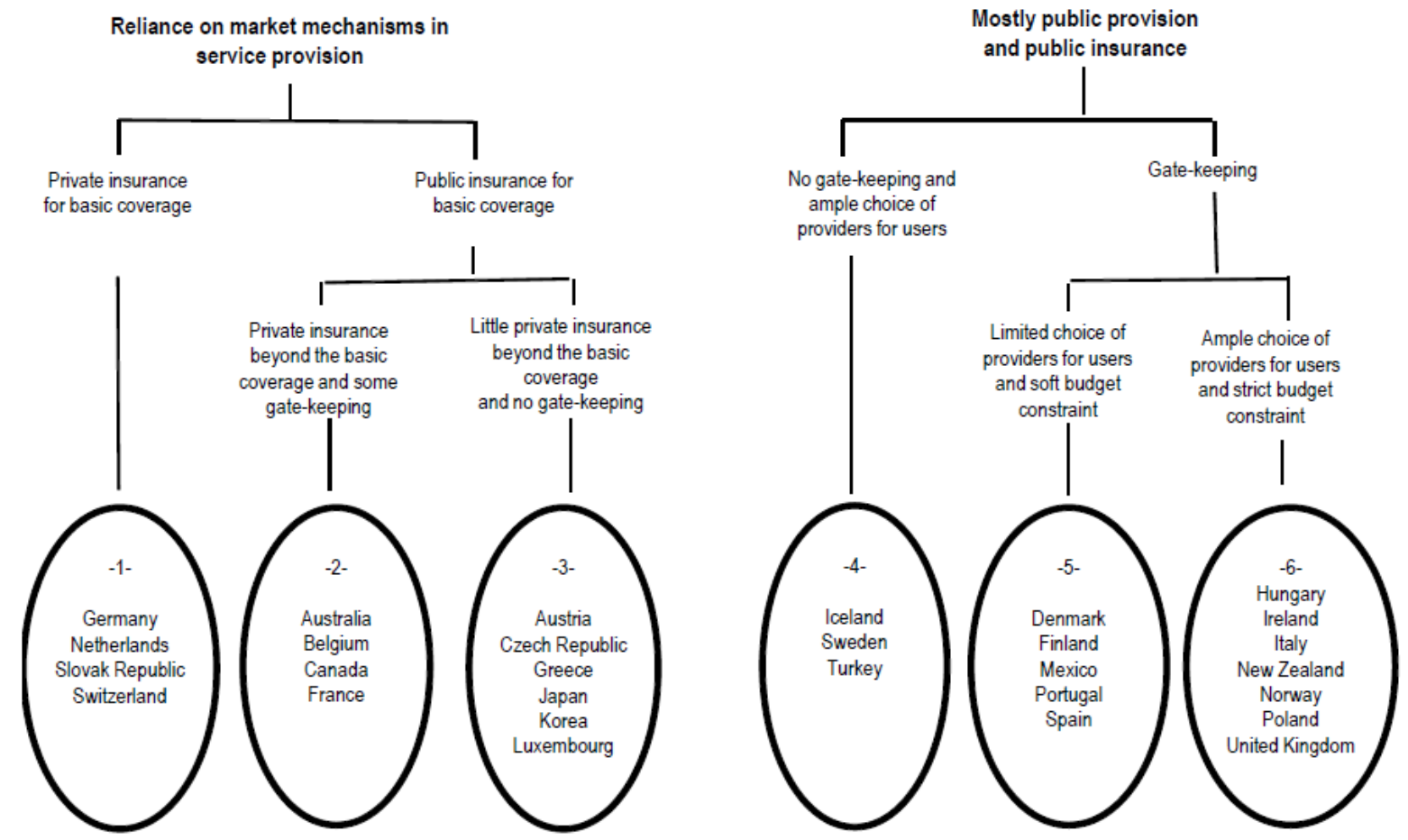
The 20 indicators they used to group the countries are developed from the results of a questionnaire of 269 mainly qualitative items collecting information on the healthcare system characteristics and was sent out by the OECD to its members in 2008 with all apart from the United States responding by early 2009. The results of the 29 responded countries were validated by checking for consistency with experts' knowledge and understanding as well as ensuring cross-country consistency (Paris, Devaux, \& Wei, 2010). Using this recent identification of OECD countries with similar healthcare institutions, together with data on healthcare spending and controls for other factors that have been found to be, or are likely to be, related to healthcare spending, it is possible to identify the extent to which intuitional differences affect healthcare spending and which aspects are most significant.

\section{Methodology}

As is clear from the literature review, most existing research has concentrated on high-income, developed countries, however, it appears that the healthcare systems of low and middle-income countries are characterised by the same issues so findings and implications coming from looking at highincome countries should still, to a certain extent, be relevant to other countries. This paper will therefore concentrate on high-income, developed countries and this also simplifies cross country comparisons as it is most appropriate to compare countries that have similar levels of healthcare quality (although this will still need to be taken into account) but still differ significantly in terms of total spending levels.

This paper will therefore focus on a selection of developed OECD countries that have healthcare systems that sometimes appear to be very different from an institutional perspective but are relatively similar in terms of quality. The institutional differences between healthcare systems in terms of market structures, competition levels, and government intervention and their role on healthcare spending can be explored by looking for evidence of differences between the six groups of countries sharing similar healthcare institutions identified by Joumard, André, \& Nicq (2010). The specifics of how they grouped the 29 countries being covered earlier in the literature review section. The sample includes all OECD countries in 2009 except the United States as they did not respond to the questionnaire that was used to form institutional indicators and group countries.

This omission of the US is unfortunate as it has the highest healthcare spending per capita in the world and is the subject of much of the existing literature. However, group 1 consists of countries reliant on extensive private market sector healthcare provision whilst also relying on basic healthcare insurance coverage from the private sector. The exiting literature appears to indicate this would be a suitable characterisation for the US, especially in 2009 before more recent reforms. Naderi \& Meier (2010) note that in the US "voluntary, private insurance represents the principal system of coverage for the majority of the population" and that "there is a palpable absence of government regulation" again suggesting that group 1 appears to be most appropriate categorisation. However, they also note that the US has "an exceedingly high number of individuals without health insurance" and is in many ways different to the system in the Netherlands, a group 1 country, such as it not guaranteeing universal coverage (Naderi \& Meier, 2010). These factors suggest that the US may be extreme, even in relation to the group 1 countries and possibly belongs in a group of its own, making meaningful comparisons difficult. There is also the complicating matter of institutions across the US being far from fixed across the country with

\footnotetext{
$6 \quad$\begin{tabular}{l|l} 
Marble \\
Research
\end{tabular} Paper
} 
policies and regulations differing between states. Due to these issues, analyses will be conducted with the original 29 country sample excluding the US as well as with a larger 30 country sample including the US as a group 1 country. This will therefore allow observation of the impact of including the US as a group 1 country as opposed to excluding it entirely.

As this paper looks at actual spending levels between different countries, the dependent variable that is most appropriate to look at is per capita total healthcare spending in current US dollars in purchasing power parity, PPP, terms. Data on this was obtained from the OECD Statistics database (OECD, n.d.). As the country groupings were formed from surveys and data obtained in 2009 and early 2010 the subsequent analysis was carried out using data from 2009 although for Turkey this was not available and data from 2008 was used instead.

As well as the independent variable of the country groupings, other control variables are included to better isolate the effect of the country groupings. Previous literature finds a clear relation between average income in the form of GDP per capita and health expenditures across countries. To account for this, GDP per capita in current US dollars in PPP terms for 2009 is included, with data again obtained from the OECD statistics database (OECD, n.d.).

Life expectancy at birth is often used in the existing literature as a good indicator for the overall effectiveness of a healthcare system and the direction of any relationship with health expenditures is almost certainly not one-way and is instead more complex with it being endogenous to an extent. It is intuitive that higher health care spending would result in a higher life expectancy but it is also intuitive that if a higher life expectancy signals a population that makes "healthier" choices then one would expect a negative effect on healthcare spending. Irrespective of the precise relationship, including life expectancy at birth as a control variable allows the effect of the country groupings to be observed more directly as it effectively allows us to observe what impact the groupings have on spending in a scenario where all countries have the same level of overall effectiveness as measured by life expectancy at birth. Again, data from 2009 that is obtained from the OECD is used (OECD, n.d.).

The review of the existing literature has shown that tobacco use, obesity and alcohol consumption are the three lifestyle factors that are most commonly looked at in relation to healthcare outcomes and spending as there is evidence that higher rates of any of these can contribute to worse health outcomes and associated higher spending. It is unlikely that these factors are not completely exogenous as one can imagine an efficient, low-cost healthcare system that does well at prioritising spending on relatively cheap preventative measures such as offering "quit smoking" aids having better statistics for these lifestyle factors. Despite the uncertainty of the exact relationship and direction between these factors and healthcare spending, it is still appropriate to include them as additional controls as the precise relationships are not the subject of this paper.

OECD data is obtained on the percentage of the population aged $15+$ who are daily smokers, the measured obese population proportion and litres of alcohol per capita consumed per year by those aged 15 or over. Again, data from 2009 is used (OECD, n.d.). 
The exiting literature also notes that the population demographics of a country can also play a role in determining healthcare spending with the elderly generally requiring more (and more expensive) treatment. Therefore, the proportion of the population that is aged 65 and over is included as a control variable. Again, data from 2009 is obtained from the OECD (OECD, n.d.).

Different ordinary least squares regression (OLS) analyses are conducted, regressing health expenditure per capita \$US PPP against combinations of the dummy variables for the country groupings 1 to 6 , a constant, GDP per capita in \$US PPP, life expectancy at birth, the proportion of the population aged 65 and over, and the three lifestyle factors listed before.

First, regressions are run regressing health expenditure per capita \$US PPP against only a constant and GDP per capita in \$US PPP in order to check the relation between GDP per capita and health expenditure. Next, the dummy variables for the groups are included and different regressions are run showing the impact of different specifications such as including the controls for lifestyle factors. The different specifications are explained in detail in the following results section.

\section{Results}

Table 1 shows the results of a regression analysis that looks at three specifications; GDP per capita alone (regressions 1 and 2), a model with GDP per capita as well as life expectancy at birth and dummy variables for groups 1 to 6 (regressions 3 and 4), and the "complete" model with additional lifestyle controls and a control for the proportion of the population aged 65 and over (regressions 5 and 6 ). For each of these specifications the regression is run for the original sample of 29 countries and the extended sample of 30 countries including the US and assuming the US is a group 1 country.

Table 1. OLS regression analysis, dependent variable: health expenditure per capita \$US PPP.

\begin{tabular}{|c|c|c|c|c|c|c|c|c|c|c|c|c|}
\hline & \multicolumn{2}{|c|}{ (1) } & \multicolumn{2}{|c|}{ (2) } & \multicolumn{2}{|l|}{ (3) } & \multicolumn{2}{|c|}{ (4) } & \multicolumn{2}{|l|}{ (5) } & \multicolumn{2}{|c|}{ (6) } \\
\hline & B & SE B & B & SE B & B & SE B & B & SE B & B & SE B & B & SE B \\
\hline Constant & 468.76 & 366.27 & 287.99 & 510.94 & & & & & & & & \\
\hline GDP per capita & $0.077 * * *$ & 0.0097 & $0.085 * * *$ & 0.014 & $0.054 * * *$ & 0.0095 & $0.066 * * *$ & 0.015 & $0.058 * * *$ & 0.011 & $0.063^{* * *}$ & 0.017 \\
\hline Life expectancy & & & & & $179.54 * * *$ & 47.78 & 125.07 & 77.04 & $148.91 * *$ & 66.00 & 156.38 & 100.49 \\
\hline$\%$ Obese & & & & & & & & & 3.53 & 20.21 & $53.11^{*}$ & 26.77 \\
\hline \% Smokers & & & & & & & & & 14.41 & 24.44 & -5.84 & 36.70 \\
\hline $\begin{array}{l}\text { Alcohol } \\
\text { consumption }\end{array}$ & & & & & & & & & 4.61 & 59.87 & -81.95 & 87.24 \\
\hline$\% 65+$ & & & & & & & & & 31.07 & 38.53 & 49.60 & 58.40 \\
\hline Group 1 & & & & & $-12450.77 * * *$ & 3607.13 & -7897.46 & 5792.91 & $-11071.42 * *$ & 4926.59 & -11117.86 & 7502.69 \\
\hline Group 2 & & & & & $-12773.48 * * *$ & 3673.36 & -8807.06 & 5933.62 & $-11318.84 * *$ & 5057.01 & -12105.96 & 7697.55 \\
\hline Group 3 & & & & & $-13538.48 * * *$ & 3632.12 & -9625.45 & 5867.42 & $-12216.28^{* *}$ & 4966.91 & -12669.29 & 7562.84 \\
\hline Group 4 & & & & & $-13234.50 * * *$ & 3621.21 & -9291.15 & 5847.81 & $-11686.23 * *$ & 5004.61 & -12890.34 & 7612.61 \\
\hline Group 5 & & & & & $-13043.27 * * *$ & 3613.69 & -9096.57 & 5835.11 & $-11598.71 * *$ & 4980.43 & -12504.95 & 7579.62 \\
\hline Group 6 & & & & & $-13082.95 * * *$ & 3603.85 & -9168.08 & 5820.22 & $-11702.78^{* *}$ & 4972.46 & -12520.95 & 7568.41 \\
\hline $\mathbf{N}$ & 29 & & 30 & & 29 & & 30 & & 29 & & 30 & \\
\hline $\mathbf{R}^{2}$ & $0.7 C$ & & 0.59 & & 0.87 & & 0.7 & & 0.88 & & 0.8 & \\
\hline Adjusted $\mathbf{R}^{2}$ & $0.6 \mathrm{~s}$ & & 0.57 & & 0.83 & & 0.6 & & 0.80 & & 0.6 & \\
\hline $\begin{array}{l}\text { Wald test F- } \\
\text { statistic for } \\
\text { equality in the } \\
\text { group } \\
\text { coefficients }\end{array}$ & & & & & $2.70 * *$ & & 2.71 & & $2.28^{*}$ & & 2.59 & \\
\hline
\end{tabular}

Note: ${ }^{*} \mathrm{p}<0.10 .{ }^{*} \mathrm{p} p<0.05 . * * * \mathrm{p}<0.01$. 
In regressions 3 to 6 the inclusion of dummy variables for each group and no constant implies that the coefficient for each group corresponds to the constant term for each group. Therefore, if there are no level differences between the groups after controlling for the other variables, the coefficients for each group would be expected to be equal. This null hypothesis can be tested using a Wald test and the Fstatistic as well as its significance are reported in Table 1.

The GDP per capita coefficient is positive and statistically significant at at least the $1 \%$ significance level in all the regressions. When it is included as the only independent variable along with a constant, it is able to explain around $70 \%$ of the variation between the 29 countries excluding the US (regression 1 ) but this falls to around $60 \%$ when the US is included (regression 2 ).

The additional lifestyle controls and control for the proportion of the population aged 65 and over appear to have a very limited impact on the 29 country sample excluding the US with the $\mathrm{R}^{2}$ increasing only slightly from 0.87 to 0.88 and the adjusted $R^{2}$ falling from 0.83 to 0.80 between (3) and (5) and the controls being statistically insignificant, at least individually, in (5). They have more of an impact on the 30 country sample including the US with the $R^{2}$ increasing from 0.76 to 0.80 . However, the fact that the adjusted $R^{2}$ remains at 0.68 between (4) and (6) suggests that in this sample the additional controls again provide little additional explanatory power.

In both specifications, the coefficients for the dummy variables for each group are negative and statistically significant at at least the $5 \%$ significance level in the 29 country sample excluding the US (regressions 3 and 5). When the US is included, none of the coefficients are significant at at least the $10 \%$ level (regressions 4 and 6 ). However, as these coefficients effectively correspond to the constant term associated with each group, their levels and reported statistical significance related to the null hypothesis of them being equal to 0 are not of particular interest. What is more important to look at is the differences, or lack of, between these coefficients.

The Wald test testing the null hypothesis that these group coefficients are equal to each other finds that this null hypothesis can be rejected for both sample sets, including and excluding the US, at at least the $10 \%$ significance level in the model with the additional controls (regressions 5 and 6 ). In the model with fewer controls (regressions 3 and 4), it can be rejected at the $5 \%$ significance level for both samples. Consequently, there is strong evidence that there are differences in spending levels between the groups.

The coefficient for group 1 is the highest (least negative) in all the regressions, which suggests that group 1 countries have higher healthcare expenditures after controlling for several possible confounding variables. To test this more completely, the regressions 3 to 6 can be specified as having a constant term in place of the group 1 dummy variable with the other repressors remaining intact. This implies that the regression takes group 1, extensive private provision and private insurance, as a baseline and the coefficients for the dummy variables relating to groups 2 to 6 correspond to changes in expenditure as a result from a country being in one of these other groups whilst holding the other variables constant. The results of this regression analysis are shown in Table 2. 
Table 2. OLS regression analysis, dependent variable: health expenditure per capita \$US PPP, Group 1 baseline.

\begin{tabular}{|c|c|c|c|c|c|c|c|c|}
\hline & \multicolumn{2}{|c|}{ (7) } & \multicolumn{2}{|c|}{ (8) } & \multicolumn{2}{|c|}{ (9) } & \multicolumn{2}{|c|}{ (10) } \\
\hline & B & SE B & B & SE B & B & SE B & B & SE B \\
\hline Constant & -12450.77 & 3607.13 & -7897.46 & 5792.91 & $-11071.42 * *$ & 4926.59 & -11117.86 & 7502.69 \\
\hline GDP per capita & $0.054 * * *$ & 0.0095 & $0.066 * * *$ & 0.015 & $0.058 * * *$ & 0.011 & $0.063^{* * * *}$ & 0.02 \\
\hline Life expectancy & $179.54 * * *$ & 47.78 & 125.07 & 77.04 & $148.91 * *$ & 66.00 & 156.38 & 100.49 \\
\hline$\%$ Obese & & & & & 3.53 & 20.21 & $53.11^{*}$ & 26.77 \\
\hline$\%$ Smokers & & & & & 14.41 & 24.44 & -5.84 & 36.70 \\
\hline Alcohol consumption & & & & & 4.61 & 59.87 & -81.95 & 87.24 \\
\hline$\% 65+$ & & & & & 31.07 & 38.53 & 49.60 & 58.40 \\
\hline Group 2 & -322.72 & 354.92 & -909.60 & 561.03 & -247.42 & 406.00 & -988.10 & 575.22 \\
\hline Group 3 & $-1087.71^{* * *}$ & 319.47 & $-1727.99 * * *$ & 495.78 & $-1144.86 * * *$ & 360.41 & $-1551.43^{* * *}$ & 534.58 \\
\hline Group 4 & $-783.73^{*}$ & 380.71 & $-1393.69 * *$ & 603.22 & -614.81 & 530.62 & $-1772.48 * *$ & 726.22 \\
\hline Group 5 & $-592.50 *$ & 336.93 & $-1199.12 * *$ & 528.78 & -527.29 & 395.65 & $-1387.09 * *$ & 542.00 \\
\hline Group 6 & $-632.18^{*}$ & 310.82 & $-1270.63 * *$ & 480.93 & $-631.36 *$ & 355.90 & $-1403.09 * * *$ & 487.79 \\
\hline $\mathbf{N}$ & \multicolumn{2}{|c|}{29} & \multicolumn{2}{|c|}{30} & \multicolumn{2}{|c|}{29} & \multicolumn{2}{|c|}{30} \\
\hline $\mathbf{R}^{2}$ & \multicolumn{2}{|c|}{0.87} & \multicolumn{2}{|c|}{0.76} & \multicolumn{2}{|c|}{0.88} & \multicolumn{2}{|c|}{0.80} \\
\hline Adjusted $\mathbf{R}^{2}$ & \multicolumn{2}{|c|}{0.83} & \multicolumn{2}{|c|}{0.68} & \multicolumn{2}{|c|}{0.80} & \multicolumn{2}{|c|}{0.68} \\
\hline
\end{tabular}

Note: $* p<0.10 . * * p<0.05 . * * * p<0.01$.

In both specifications and both samples, the coefficients for the dummy variables (which correspond to the effect on healthcare spending of a country being in a group other than the baseline group of group 1 ) are negative for all the groups 2 to 6 . The results are however not always statistically significant.

The difference between group 1 and 3 is always statistically significant at the $1 \%$ level however the difference between group 1 and 2 is never statistically significant at any reasonable level, i.e. 10\%. The statistical significance of the differences between group 1 and groups 4,5 and 6 is dependent on whether the additional controls are included and on the inclusion of the US as a group 1 country. In general, the differences become more statistically significant when the US is included with them all being significant at at least the $5 \%$ significance level in both models when the US is included as a group 1 country (regressions 8 and 10).

The coefficients of the repressors other than the group dummy variables, the $R^{2}$ values and adjusted $R^{2}$ values for the models are the same as seen before as these regressions are simply alternative specifications of regressions 3 to 6 .

At least some of the differences in healthcare spending implied by the coefficients on the group dummy variables are economically significant. Taking the most conservative coefficient for group 3 from the regression without additional controls and the sample excluding the US (regression 7), it implies that a country that is in group 3 (mostly private provision but mostly public insurance) will have \$1088 lower healthcare spending per capita than a country in group 1 (mostly private provision and insurance) that has the same wealth level in terms GDP per capita and the same overall healthcare effectiveness and

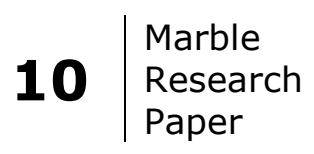


outcomes in terms of life expectancy at birth. With healthcare spending per capita across the sample of 29 countries, i.e. excluding the US, having a mean of $\$ 3183$, this equates to $34 \%$ lower healthcare spending.

The analysis in Table 2 compares groups 2 to 6 with group 1 as a baseline and therefore allows identification of significant differences between group 1 with the other groups. Through alternative specifications, different groups can be specified as the baseline group that the other groups are compared to and all possible combinations of differences between groups can be tested for statistical significance. This analysis is done for both models (with and without additional controls) and both samples (29 countries excluding the US and 30 countries with the US included as a group 1 country) with a summary of the exact results being reported in the appendix of this paper in Tables A1-4.

What is found is that there is limited evidence of differences among groups 2 to 6 (the significant differences between group 1 and the other groups having already been shown and analysed, see Table 2 ). The only differences that are statistically significant at at least the $10 \%$ level are between groups 2 and 3 which is significant at the $5 \%$ level in both models, with and without additional controls, with the original 29 country sample excluding the US. When the US is included as a group 1 country, this difference is no longer statistically significant. In both cases group 3 has a negative coefficient, implying lower healthcare spending, when compared to the baseline of group 2.

As well as looking at the differences between each group simultaneously, it is also useful to look at the difference between each individual group and the other groups taken as a whole, e.g. group 1 against groups 2 to 6 taken as one group. This can be accomplished by running a separate regression for each group with only the dummy variable for that group in the repressors as well a constant term. The results of such an analysis are shown in Table 3 using a model without the additional controls as they were found to add little explanatory power in the previous regression analyses and with the original 29 country sample excluding the US.

Table 3. OLS regression analysis, dependent variable: health expenditure per capita \$US PPP, individual group effect compared to other groups taken as a whole.

\begin{tabular}{|c|c|c|c|c|c|c|c|c|c|c|c|c|}
\hline & \multicolumn{2}{|c|}{ (11) } & \multicolumn{2}{|c|}{ (12) } & \multicolumn{2}{|c|}{ (13) } & \multicolumn{2}{|c|}{ (14) } & \multicolumn{2}{|c|}{ (15) } & \multicolumn{2}{|c|}{ (16) } \\
\hline & B & SE B & B & SE B & B & SE B & B & SE B & B & SE B & B & SE B \\
\hline Constant & $-13732 * * *$ & 3699.04 & $-12005^{* * *}$ & 4115.42 & $-13269 * * *$ & 3661.46 & $-12834 * * *$ & 4108.88 & $-12914 * * *$ & 4139.45 & $-12831 * * *$ & 4160.18 \\
\hline GDP per capita & $0.052 * * *$ & 0.0097 & $0.055 * * *$ & 0.011 & $0.058 * * *$ & 0.0097 & $0.054 * * *$ & 0.011 & $0.055 * * *$ & 0.011 & $0.055 * * *$ & 0.011 \\
\hline Life expectancy & $188.06 * * *$ & 48.94 & $165.29 * * *$ & 54.51 & $182.44 * * *$ & 48.45 & $177.09 * * *$ & 54.35 & $177.54 * * *$ & 54.72 & $176.68 * * *$ & 54.94 \\
\hline Group 1 & $712.91 * *$ & 280.34 & & & & & & & & & & \\
\hline Group 2 & & & 346.41 & 311.91 & & & & & & & & \\
\hline Group 3 & & & & & $-627.56 * *$ & 238.70 & & & & & & \\
\hline Group 4 & & & & & & & -201.24 & 353.04 & & & & \\
\hline Group 5 & & & & & & & & & 16.35 & 290.14 & & \\
\hline Group 6 & & & & & & & & & & & -36.61 & 252.89 \\
\hline $\mathbf{N}$ & 29 & & 29 & & 29 & & 29 & & Vote: $* p<39$ & 10. $* * p<$ & $0.05 . * * * 29$ & ${ }^{9}<0.01$ \\
\hline $\mathbf{R}^{2}$ & 0.8 & & 0.8 & & 0.8 & & 0.7 & & 0.7 & & 0.7 & \\
\hline Adjusted $\mathrm{R}^{2}$ & 0.8 & & 0.7 & & 0.8 & & 0.7 & & 0.7 & & 0.7 & \\
\hline
\end{tabular}


Looking at Table 3, it is observed that the coefficients for GDP per capita and life expectancy are very similar across the different regressions and are always highly statistically significant, indicating robustness.

Only group 1 and group 3 are found to be statistically significant at the $5 \%$ level with all the other groups being insignificant. This suggests that only groups 1 and 3 are significantly different from the other groups with the other groups not showing a significant difference from the other groups when they are taken as a whole. As an example for clarification, group 1 is significantly different from the other groups, 2 to 6, when they are considered as one group, i.e. not group 1 .

Group 1 has a positive coefficient indicating higher healthcare spending per capita and group 3 has a negative coefficient indicating lower healthcare spending per capita. These results are consistent with the results found before.

\section{Discussion}

The results of the regressions including just GDP per capita as the sole independent variable confirm the findings of Reinhardt, Hussey, \& Anderson (2004), as well as other studies, that GDP per capita appears to be one of the most important factors in explaining variation in healthcare spending. Their explanation for this being that a higher GDP per capita represents higher ability to pay. Their regression analysis indicated that it can account for about $90 \%\left(R^{2}=0.94\right)$ of the variation in spending across the 30 OECD countries in 2001 although the results of this paper appear to be suggest this figure is around $60 \%\left(R^{2}\right.$ $=0.97$ ) for the same 30 OECD countries in 2009 (regression 2). However, in their regression Luxembourg and Norway were excluded as "Luxembourg's GDP is unusually high from international financial services, and Norway's is unusually high by virtue of its oil revenues" (Reinhardt, Hussey, \& Anderson, 2004). Excluding Luxembourg and Norway from the regression of the 2009 data and hence repeating their regression exactly (there have been no new OECD members between 2001 and 2009) gives an $R^{2}$ of 0.82 . There is therefore still strong evidence that GDP per capita is a strong determinant of total healthcare spending, however, there is some evidence that the relation is less strong in 2009 than in 2001. This would imply that other factors such as the institutional differences that are the topic of this paper may have become more important in relation to determining healthcare spending.

The results show that after controlling for differences in GDP and healthcare quality/outcomes through life expectancy, there are some significant differences between the six groups of OECD countries in 2009 that share similar healthcare institutions identified by Joumard, André, \& Nicq (2010). This therefore suggests that healthcare institutions do play a significant role in determining healthcare spending.

Adding further controls for lifestyle factors such as smoking, alcohol consumption and obesity as well as the proportion of the population aged 65 and over does not appear to significantly increase the predictive capability compared to a model without these additional controls, suggesting that these controls play a relatively insignificant role in determining healthcare spending.

\footnotetext{
$12 \mid$\begin{tabular}{l|l} 
Marble \\
Research \\
Paper
\end{tabular}
} 
There is strong evidence that having the institutional characteristics typical of a group 1 country, namely, reliance on private provision and private insurance, is associated with having the highest total healthcare expenditures, a finding that is robust to different specifications, the inclusion of additional controls and the inclusion or exclusion of the US as a group 1 country. Part of this higher spending is likely due to administrative costs being higher for countries relying on private insurance for basic coverage, i.e. group 1 (Joumard, André, \& Nicq, 2010). In 2007 administrative costs were found to be less than $2 \%$ of total healthcare spending in Denmark, Hungary, Italy, Norway and Portugal which are all in either group 5 or 6 whereas in some countries such as the United States, administrative costs exceeded $7 \%$ of total spending (Joumard, André, \& Nicq, 2010). These figures suggest that in some countries administrative costs do make up a significant proportion of healthcare spending and there is room for significant savings. Reinhardt, Hussey, \& Anderson (2004) also found that administrative complexity and related costs make up a significant proportion of spending in some countries with the US healthcare system being described as an "administrative monstrosity".

Group 2 of private provision but public insurance for basic coverage with significant supplementary private insurance was never found to be significantly different from group 1 . This is probably because there is still extensive private insurance and the only distinction from group 1 is that it there exists some basic public insurance coverage, therefore it shares many institutional characteristics with group 1.

There is evidence that group 3 with private provision but extensive public insurance with little supplementary private insurance has the lowest costs with the difference from group 1 being statistically significant and this finding being robust to different specifications, the inclusion of additional controls and the inclusion or exclusion of the US as a group 1 country. Furthermore, it is found that group 3 has significantly lower spending when compared to the other groups taken together. Healthcare spending may be reduced due to what is predominately a single-payer system with the government providing the vast majority of healthcare financing. This gives the government a great deal of buyer power which should theoretically give the government a greater ability to negotiate lower prices, even in a situation where there is mainly private provision of services. Relying less on private insurance and more on public insurance should also limit the impact of possible market failures such as adverse selection in the private insurance market caused by an information asymmetry between the consumer and the insurer regarding the consumer's health condition. The existence of which could theoretically result in higher insurance premiums and higher total healthcare spending (Joumard, André, \& Nicq, 2010).

Groups 4, 5 and 6 all correspond to countries and healthcare institutions that have mostly public provision and public insurance but differ with respect to gatekeeping (where patients must first contact a primary care provider before being referred for further care), users' choice of providers and strictness of any budget constraint. No significant differences are found between these groups which suggests that in systems with mostly public provision and insurance, other institutional factors such as these play little role in determining healthcare spending. 
There is strong evidence that public provision and public insurance, as in groups 4, 5 and 6, results in significantly lower spending than reliance on private provision and private insurance as in group 1 . There is however less strong evidence for a significant difference between a situation with public provision and public insurance and the situation that appears to have the lowest total costs and only differs in the respect of having extensive private rather than public provision, that of a system relying on private provision but with extensive public insurance, group 3. Therefore, there is weak evidence for institutional differences on the provision side, in terms of private or public provision, playing a role in determining total spending.

\section{Conclusion and policy implications}

It appears that the only institutional difference that plays any significant role in accounting for healthcare spending differences around the world is the extent of public insurance (publicly/government funded healthcare) with more public insurance and less private insurance being associated with significantly lower spending after controlling for differences in wealth through GDP and healthcare quality/outcomes through life expectancy. This result is robust to the inclusion of additional controls for lifestyle factors (smoking, obesity and alcohol consumption) and the proportion of the population aged $65+$. The result is also robust to the inclusion or exclusion of the US as a group 1 country.

The results suggest that these differences are economically as well as statistically significant. A typical country with extensive private provision and insurance such as the Netherlands, Germany or the US could reduce healthcare spending by around a third by moving to a system with extensive public insurance whilst retaining extensive private provision of services.

As a policy recommendation, on the funding side, public insurance should be maximised in order to minimise total healthcare spending. Further research is however needed to identify the costs of such reforms and this is likely to vary considerably from country to country. There is also the issue of whether increasing public insurance and the associated tax increases would be supported by public opinion, as well as the feasibility of the relevant reforms under the different political institutions that exist in different countries.

Another limitation of this research is that it only considers the impact on total spending whilst keeping the healthcare outcome of life expectancy fixed. There are likely other aspects that should be considered such as health inequalities and the quality of life offered under different systems as this may differ from life expectancy but is still an outcome that many would argue is important to consider. For example, a system may spend more by spending more on treatment that does not extend a patient's life but does significantly improve their quality of life whilst they are alive. However, quality of life is inherently a very subjective measure and is therefore an example of the difficulty in controlling for many possible healthcare outcome measures that are hard to measure as objectively as life expectancy can be. Future research should therefore look how this limitation can be addressed.

\footnotetext{
14 \begin{tabular}{l|l} 
Marble \\
Research \\
Paper
\end{tabular}
} 
The impact on research and development spending should also be considered as it is likely that the incentives for investment will differ between systems with different institutional characteristics. This is relevant when looking at the likelihood of innovations that would almost certainly affect healthcare systems and spending in the long term.

This research also only looked at 30 predominantly high-income countries and used six rather broad categories to group these countries so it would be beneficial for future research to look at categorising more countries and look at the role of more precisely defined institutional differences.

The categories and other data used date back to 2009 so it may well be the case that there have since been significant institutional changes in certain countries. Hence, it would be good to look at collecting more recent data on the state of healthcare institutions across countries. This would also allow the examination of the impact of any reforms and allow the conclusions and policy implications of this paper to be tested. 


\section{References}

Anderson, G. F., Hurst, J., Hussey, P. S., \& Jee-Hughes, M. (2000). Health spending and outcomes: trends in OECD countries, 1960-1998. Health Affairs, 19(3), 150-157. doi: $10.1377 /$ hlthaff.19.3.150

Anderson, G. F., Reinhardt, U. E., Hussey, P. S., \& Petrosyan, V. (2003). It's the prices, stupid: why the United States is so different from other countries. Health Affairs, 22(3), 89-105. doi: $10.1377 /$ hlthaff.22.3.89

Basu, S., Andrews, J., Kishore, S., Panjabi, R., \& Stuckler, D. (2012). Comparative performance of private and public healthcare systems in low-and middle-income countries: a systematic review. PLoS medicine, 9(6), e1001244. doi:10.1371/journal.pmed.1001244

Frank, R. G. (2001). Prescription drug prices: why do some pay more than others do? Health Affairs, 20(2), 115-128. doi:10.1377/hlthaff.20.2.115

Hashimoto, H., Ikegami, N., Shibuya, K., Izumida, N., Noguchi, H., Yasunaga, H., . . . Reich, M. R. (2011). Cost containment and quality of care in Japan: is there a trade-off? The Lancet, 378(9797), 1174-1182. doi:10.1016/S0140-6736(11)60987-2

Joumard, I., André, C., \& Nicq, C. (2010). Health care systems: efficiency and institutions. OECD Economics Department Working Papers, No. 769. doi:10.1787/5kmfp51f5f9t-en

Motta, M. (2004). Competition Policy: Theory and Practice. Cambridge: Cambridge University Press.

Naderi, P. S., \& Meier, B. D. (2010). Privatization within the Dutch context: A comparison of the health insurance systems of the Netherlands and the United States. Health, 14(6), 603-618. doi: $10.1177 / 1363459309360790$

OECD. (2014). OECD Health Statistics 2014 - Frequently Requested Data. Retrieved May 4, 2015, from OECD: http://www.oecd.org/els/health-systems/oecd-health-statistics-2014-frequentlyrequested-data.htm

OECD. (n.d.). Health Expenditure - OECD. Retrieved May 3, 2015, from OECD: http://www.oecd.org/els/health-systems/health-expenditure.htm

OECD. (n.d.). OECD Statistics. Retrieved May 10, 2015, from OECD: http://stats.oecd.org/

Paris, V., Devaux, M., \& Wei, L. (2010). Health systems institutional characteristics: a survey of 29 OECD Countries. OECD Health Working Papers. doi:10.1787/5kmfxfq9qbnr-en

Phelps, C. E. (2012). Health Economics (5th ed.). Pearson.

Reinhardt, U. E., Hussey, P. S., \& Anderson, G. F. (2004). US health care spending in an international context. Health Affairs, 23(3), 10-25. doi:10.1377/hlthaff.23.3.10

Squires, D. A. (2012). Explaining high health care spending in the United States: an international comparison of supply, utilization, prices, and quality. Issue brief (Commonwealth Fund), 10, 114.

Stabile, M., Thomson, S., Allin, S., Boyle, S., Busse, R., Chevreul, K., . . . Mossialos, E. (2013). Health care cost containment strategies used in four other high-income countries hold lessons for the United States. Health Affairs, 32(4), 643-652. doi:10.1377/hlthaff.2012.1252

$16 \mid$\begin{tabular}{l|l} 
Marble \\
Research \\
Paper
\end{tabular} 


\section{Appendix}

Table A1. Summary of the group dummy variable coefficients in different OLS regressions with different baseline groups, $\mathrm{N}=29$, no additional controls.

\begin{tabular}{|c|c|c|c|c|c|c|c|c|c|c|c|c|}
\hline & \multicolumn{12}{|c|}{ Baseline group } \\
\hline & \multicolumn{2}{|c|}{ Group 1} & \multicolumn{2}{|c|}{ Group 2} & \multicolumn{2}{|c|}{ Group 3} & \multicolumn{2}{|c|}{ Group 4} & \multicolumn{2}{|c|}{ Group 5} & \multicolumn{2}{|c|}{ Group 6} \\
\hline & B & SE B & B & SE B & B & SE B & B & SE B & B & SE B & B & SE B \\
\hline \multicolumn{13}{|l|}{ Group 1} \\
\hline \multicolumn{13}{|l|}{ Group 2} \\
\hline Group 3 & $-1087.71 * * *$ & 319.47 & $-765.00 * *$ & 320.86 & & & & & & & & \\
\hline Group 4 & $-783.73^{*}$ & 380.71 & & & & & & & & & & \\
\hline Group 5 & $-592.50 *$ & 336.93 & & & & & & & & & & \\
\hline Group 6 & $-632.18^{*}$ & 310.82 & & & & & & & & & & \\
\hline
\end{tabular}

Table A2. Summary of the group dummy variable coefficients in different OLS regressions with different baseline groups, $\mathrm{N}=30$, no additional controls.

\begin{tabular}{|c|c|c|c|c|c|c|c|c|c|c|c|c|}
\hline & \multicolumn{12}{|c|}{ Baseline group } \\
\hline & \multicolumn{2}{|c|}{ Group 1} & \multicolumn{2}{|c|}{ Group 2} & \multicolumn{2}{|c|}{ Group 3} & \multicolumn{2}{|c|}{ Group 4} & \multicolumn{2}{|c|}{ Group 5} & \multicolumn{2}{|c|}{ Group 6} \\
\hline & B & SE B & B & SE B & B & SE B & B & SE B & B & SE B & B & SE B \\
\hline \multicolumn{13}{|l|}{ Group 1} \\
\hline \multicolumn{13}{|l|}{ Group 2} \\
\hline Group 3 & $-1727.99 * * *$ & 495.78 & & & & & & & & & & \\
\hline Group 4 & $-1393.69 * *$ & 603.22 & & & & & & & & & & \\
\hline Group 5 & $-1199.12^{* *}$ & 528.78 & & & & & & & & & & \\
\hline Group 6 & $-1270.63 * *$ & 480.93 & & & & & & & & & & \\
\hline
\end{tabular}

Table A3. Summary of the group dummy variable coefficients in different OLS regressions with different baseline groups, $\mathrm{N}=29$, additional controls.

\begin{tabular}{|c|c|c|c|c|c|c|c|c|c|c|c|}
\hline & \multicolumn{11}{|c|}{ Baseline group } \\
\hline & \multicolumn{2}{|c|}{ Group 1} & \multicolumn{2}{|c|}{ Group 2} & \multicolumn{2}{|c|}{ Group 3} & Group 4 & \multicolumn{2}{|c|}{ Group 5} & \multicolumn{2}{|c|}{ Group 6} \\
\hline & B & SE B & B & SE B & B & SE B & SE B & B & SE B & B & SE B \\
\hline \multicolumn{12}{|l|}{ Group 1} \\
\hline \multicolumn{12}{|l|}{ Group 2} \\
\hline Group 3 & $-1144.86 * * *$ & 360.41 & $-897.44 * *$ & 398.43 & & & & & & & \\
\hline \multicolumn{12}{|l|}{ Group 4} \\
\hline \multicolumn{12}{|l|}{ Group 5} \\
\hline Group 6 & -631.36 & 355.90 & & & & & & & & & \\
\hline
\end{tabular}

Table A4. Summary of the group dummy variable coefficients in different OLS regressions with different baseline groups, $\mathrm{N}=30$, additional controls

\begin{tabular}{|c|c|c|c|c|c|c|c|c|c|c|c|c|}
\hline & \multicolumn{12}{|c|}{ Baseline group } \\
\hline & \multicolumn{2}{|c|}{ Group 1} & \multicolumn{2}{|c|}{ Group 2} & \multicolumn{2}{|c|}{ Group 3} & \multicolumn{2}{|c|}{ Group 4} & \multicolumn{2}{|c|}{ Group 5} & \multicolumn{2}{|c|}{ Group 6} \\
\hline & B & SE B & B & SE B & B & SE B & B & SE B & B & SE B & B & SE B \\
\hline \multicolumn{13}{|l|}{ Group 1} \\
\hline \multicolumn{13}{|l|}{ Group 2} \\
\hline Group 3 & $-1551.43 * * *$ & 534.58 & & & & & & & & & & \\
\hline Group 4 & $-1772.48 * *$ & 726.22 & & & & & & & & & & \\
\hline Group 5 & $-1387.09 * *$ & 542.00 & & & & & & & & & & \\
\hline Group 6 & $-1403.09 * * *$ & 487.79 & & & & & & & & & & \\
\hline
\end{tabular}

Note: $* p<0.10 . * * p<0.05 . * * * p<0.01$

Only significant $(p<0.10)$ coefficients/differences reported in tables A1-4

Figures with identical magnitude and significance but with an opposite coefficient sign that exist to the other side of the diagonal are not reported for clarity in A1-4.

Healthcare Spending: The Role Of Healthcare Institutions from an International Perspective 